Article

\title{
An Assessment of European Information Technology Tools to Support Industrial Symbiosis
}

\author{
Amtul Samie Maqbool *, Francisco Mendez Alva and Greet Van Eetvelde \\ Energy \& Cluster Management, Faculty of Engineering and Architecture, Ghent University, B-9000 Ghent, \\ Belgium; Francisco.MendezAlva@UGent.be (F.M.A.); Greet.VanEetvelde@UGent.be (G.V.E.) \\ * Correspondence: Samie.Maqbool@UGent.be
}

Received: 31 October 2018; Accepted: 21 December 2018; Published: 27 December 2018

\begin{abstract}
Industrial symbiosis (IS) has proven to bring collective benefits to multiple stakeholders by minimising underutilised resources, sharing knowledge and improving business and technical processes. In Europe alone, over $€ 130$ million have been invested since 2006 in research projects that enable IS by developing a methodology, tool, software, platform or network that facilitates the uptake of IS by different economic actors. This paper discusses and assesses information technology (IT) developments for supporting IS in Europe, following the five-stage methodology of Grant et al. (2010). It provides guidance to the applicants and reviewers of publicly funded research projects by listing the developments and gaps in the newly developed IT tools for IS. Content analysis of publicly available information on 20 IS supporting IT tools reveals a strong focus on synergy identification but a lack of support for the implementation stage of IS. The paper indicates that a vast quantity of IT tools and knowledge is created during the IT tool development stage and newer IT tools now also include implicit information for identifying IS. It was found that successfully operational IT tools are either part of a national or local IS programme or owned by a private company. The paper ends with the recommendation that better mechanisms are needed to ensure that publicly funded IS-supporting IT tools successfully reach the market.
\end{abstract}

Keywords: Industrial symbiosis; IT tools; research and innovation projects

\section{Introduction}

Optimisation of industrial sites through efficiency gains, carbon and energy savings and the use of renewable energy sources is a starting point to decouple economic growth from environmental degradation. However, the system boundaries can be widened to include other industries, process sectors and neighbouring municipalities to collectively strive for resource and energy efficiency and, ultimately, aim for a circular economy. This cooperative management of resource flows between businesses and engagement of traditionally separate entities in a collective approach to competitive advantage is termed as industrial symbiosis (IS) [1,2]. It involves physical exchanges of materials, energy, water and by-products, as well as sharing social tactics at the firm and multiorganisational level [3]. This interfirm cooperation or IS [2,4,5] enables businesses to strive for a collective economic and ecological benefit that is greater than the sum of the individual benefits each company can achieve $[2,6,7]$. IS is a crosscutting field that has relevance for policies relating to resource efficiency, the low carbon and circular economy, eco-innovation, green growth, regional economic development [8] and many more [9-14].

The political will to promote industrial symbiosis has grown over the last decade to the level of being fully integrated in Europe's long-term policies and strategies. Support is provided by all levels of governance in Europe in the form of the European Resource Efficiency Platform [15], Eco-Innovation Action Plan [16], Circular Economy Roadmap France [17], National Industrial Symbiosis Programme 
(NISP) and West Midlands Industrial Symbiosis Programme (WISP) [18], etc. Europe invigorated its commitment to resource efficiency in 2011 by devising the "Roadmap to a Resource Efficient Europe" [19]. It is no surprise that IS was among the seven "top priority areas" outlined by the European Resource Efficiency Platform [15] in their 2012 Manifesto and Policy Recommendations. In 2015, the ambition to move away from a linear economy was endorsed with the release of the EU Circular Economy Package, revised in 2018 [9]. Industrial symbiosis is a means to support circularity and textbook examples of local industrial symbiosis cases like Kalundborg [6], Rotterdam [20], Tianjin [21] and many more [22-24] have repeatedly proven the potential of IS to enable progress towards the circular economy. Specifically, in Kalundborg, the symbiosis activities have resulted in reduction of $\mathrm{CO}_{2}$ emissions, water savings, biofuel production from waste, reduction of imported primary materials, etc. [25]. It stands to reason that the material benefits in Kalundborg are coupled with social and economic benefits for all the parties involved.

Despite the proven benefits of IS, only $0.1 \%$ of the 26 million European enterprises are known to be active in IS [26] based on [27]. There is still a dire need for research and innovation at all levels of social, technological and commercial fronts to reshape policies, redesign products and processes and introduce new business models to show the feasibility of the circular economy [28] and of industrial symbiosis in particular. Starting from the launch of the Energy and the Innovation Unions under Europe's 2020 Strategy in 2011, symbiosis and circularity have become key priorities in political as well as scientific agendas $[29,30]$. In this regard, different funding opportunities have been announced to incentivise the move towards a low carbon, resource efficient and circular economy, the biggest of which is the H2020 research and innovation (R\&I) funding scheme [31]. Cross-sectoral industrial symbiosis in process industries is a priority agenda for SPIRE cPPP (contractual Public Private Partnership on "Sustainable Process Industry through Resource and Energy Efficiency"), and several projects have received funding in this direction [32]. This paper helps to assess the effectiveness and impact of these initiatives in European countries, especially focusing on the development of information technology (IT) tools that support IS.

An interest in IT tools for IS has emerged on the research agenda in Europe, significantly supported by publicly funded R\&I projects. It is evident that there is a need to avoid the pitfalls faced by earlier IT tools [33]. The literature shows that IT tools for IS have faced difficulties in remaining operational. In 2000, Chertow [2] presented a literature review of tools and approaches for industrial symbiosis which included three IT tools developed as part of the Designing Industrial Ecosystem Toolkit (DIET): DIET (Designing Industrial Ecosystems Tool), FAST (FAcility Synergy Tool) and REaLiTy (Regulatory Economic and Logistics Tool). The further development of the toolkit was cancelled due to changes in budget priorities [33]. In 2010, Grant et al. published an analysis of 13 IT tools for industrial symbiosis by applying a project lifecycle approach to identify the application of these tools in different project lifecycle stages (identification, assessment, barrier removal, implementation and follow up) of a symbiosis project [33].

Of the 13 IT tools that were discussed in the paper of Grant et al. (2010) [33], only four tools were reported to be operational, three of which were developed and implemented in Europe. Presteo, SymbioGis and CRISP were still operational in 2010 [33]. Of these three, only CRISP, succeeded by Synergie ${ }^{\circledR}$, is still operational and constantly updated by the provider. In 2018, Benedict et al. identified four main barriers to IS and the corresponding IT support [34]. The first barrier is the lack of compatibility between the variety of required information from different sources and the underlying data-modelling framework of IT tools for IS creation. Second, technical feasibility and economic efficiency need to be accompanied by social aspects and mechanisms (willingness, trust, cooperation and reciprocity) that favour industrial symbiosis [35,36]. Third, the focus of most IT tools support IS identification (matchmaking), while the other project lifecycle stages of IS are often neglected. Fourth, the existing IT tools are difficult to access; often, there is no explicit mention of how and for whom the tool is available, and a gap is eminent in the literature about the management and development strategy of IT platforms [34]. 
This paper revisits the development of IT tools for IS by using the same five-stage methodology proposed by Grant et al. (2010) [33]. The aim is to objectively map the progress of IT tools for IS and conclude if the gaps in the development of IT tools for IS that have been identified in literature are being filled by newer IT tools. To reach this goal, content analysis of publicly available information on 20 IT tools was carried out and their focus on each of the five lifecycle stages of an IS project was evaluated. These five stages are, namely, synergy identification, symbiosis assessment, barrier removal, implementation and follow up [33]. To improve the robustness of the content analysis, the key performance indicators (KPIs) presented by Grant et al. (2010) for each stage were supplemented with the work of Van Eetvelde and colleagues (2005 and 2007) [5,36] and Maqbool et al. (2017) [37].

The five stages of any IS project lifecycle as outlined by Grant et al (2010) [33] are discussed below.

\subsection{Synergy Identification}

Synergy identification occurs through three primary means: new process discovery, resource (any underutilised materials, capacity, logistics, etc.) matching and relationship mimicking [33]. New process discovery refers to the identification of an industrial symbiosis enabled by technological development leading to value addition of a previously discarded by-product or waste through a novel transformation process [33]. Input-output resource matching refers to finding substitutes of resources among specific actors. Different models for synergy identification are deployed by public and private parties, such as IT-enabled identification by semantic matching [38,39], expert facilitated workshops [40] and integration of energy and material networks to achieve higher efficiency [41]. Relationship mimicking refers to the identification of an industrial symbiosis by making use of a documented case that resonates with the resources and industrial processes of the actors. However, relationship mimicking runs the risk of path dependence and, thus, research and innovation projects are crucial to the aim of innovative IS solutions.

\subsection{Symbiosis Assessment}

Symbiosis assessment evaluates the outcomes and challenges associated with IS. It is common practice to evaluate the environomic cost-benefit analysis of symbiotic activities between different partners [22]. However, other nontechnical aspects were also included in this study. This IS assessment stage was identified to be covered if the tools included:

- an assessment of compatibility of the IS activity with the national and local regulations;

- an evaluation of and distribution of economic gains between the IS partners;

- an assessment of spatial proximity between IS partners;

- a techno-environmental impact assessment of the industrial symbiosis; and

- the impact on job retention and creation under the symbiosis activity.

Focus on any one of the five aspects was considered sufficient to qualify the IT tool for achievement of this stage.

\subsection{Barrier Removal}

The barriers to industrial symbiosis have been enumerated by Van Eetvelde and colleagues [5,36], Lombardi [26] and Golev et al. [42]. Summarised by Golev et al., the barriers to IS are: lack of commitment to sustainable development, lack of information, difficulty in trust and cooperation between partners, technical infeasibility, uncertainty and inconvenience in regulatory compliance, lack of community awareness and, lastly, economic infeasibility [42]. Some of these barriers need to be removed within an individual organisation, some may need to be removed between organisations and still some are outside the bounds of the organisations, in which case, involvement of third parties to provide leverage and remove barriers is a common practice [43-45]. The barrier removal stage was considered to be covered if the IT tools focused on: 
- removing legal barriers by providing a platform to jointly enrich legal expertise development [46];

- $\quad$ simplifying access to public investment funds;

- providing information on logistics for symbiotic transfers or the potential impact on existing material and energy networks;

- information to bring about IS-related emissions reduction and improved energy efficiency; and

- improving stakeholder interaction and overcoming information barriers between unrelated sectors.

It needs to be borne in mind that these barriers are interlinked and, hence, their solutions can have effects on each other.

\subsection{Implementation}

After barrier removal, decisions need to be made for implementing a symbiosis between industries. This entails the execution of the symbiosis activity, which cannot be decoupled from the selection of a management approach. Prior to any exchange, the decision on which approach will be useful to manage the symbiosis is to be made: either it will be self-organised by the participants of IS [7] or it will be facilitated or managed by a third party, such as a park manager or IS facilitator. In the latter case, the third party acts as an intermediary enabling cooperation [20,44]. The real-time handling of resource flows is the functionality that IT tools can provide to support the execution of the symbiosis. Regarding the selection of the management approach, IT tools can provide guidelines to businesses to support decision-making. Distribution of tasks and responsibilities between partners, which is defined by the clauses in the business contracts, also forms a part of the implementation stage. It was stressed in the work of Grant et al. (2010) that this stage is almost entirely handled by the participating organisations.

\subsection{Follow Up (Review and Documentation)}

There are two main functions covered in the final stage of the symbiosis cycle: thriving and propagating. Thriving is about continuous monitoring of impact and auditing to ensure stability of the activity and regular improvement of the symbiosis process. Disseminating is about publishing the results and lessons from the symbiosis activity at different levels of detail and diffusion, from own employees to the public. Documentation and dissemination within and outside the company help to replicate industrial symbiosis in the future; external outreach helps to generate value by improving the corporate image of the company and increasing the knowledge base of society. This creates the grounds for generalising symbiosis opportunities and thus generating IS mimicking by other businesses. IS tools that include a functionality to report the impact of the synergies or provide an IS case study database via publicly available online repositories cover this stage of the IS lifecycle. The five-stage IS lifecycle does not follow a linear pattern and, thus, follow up is a crucial stage for closing the loop between the implementation and synergy identification stages.

In this paper, the selected IT tools comprised existing and upcoming IT tools. These IT tools have been or are being developed as part of in-house research and development (R\&D) projects by private companies or as a result of a publicly funded R\&I project. To limit the scope of this study, only the IT tools developed in Europe were included in the assessment. The paper provides an answer to the following four questions: Is the combination of explicit and tacit knowledge used in identifying IS opportunities in the newer IT tools? Has the user base of newer IT tools expanded? Is the substantial focus on the IS identification stage still prevalent? Finally, what are the requisites to help IT tools for IS remain operational? The objective is to provide guidance for directing public funding and resources to projects that will help bridge the gap between IT tool development and the widespread application of IS in Europe.

The following section on methodology is added to define the data collection process and the KPIs that define the assessment criteria for each IS lifecycle stage. Then, the results and discussion section discusses the 20 IT tools with respect to their focus on the stages of the IS project lifecycle and insights 
are provided for future research and innovation endeavours. Finally, in the last section of the paper, conclusions are drawn.

\section{Methodology}

\subsection{Data Collection}

An inventory of 69 items was made to start the analysis by using an internet search for the terms industrial symbiosis, resource efficiency, resource and energy optimisation and circular economy. For each entry, relevant information was sourced from the publicly available online systems: websites, brochures and related academic literature. Twenty IT tools for IS were shortlisted from the set of data. These included 3 IT tools developed as part of in-house R\&D projects by private companies; 16 IT tools developed or updated as part of a publicly funded project, 7 of which are still under development; and 1 IT tool that is being developed as part of independent academic endeavours.

Twelve IT tools that were privately owned and developed outside of Europe were excluded from the study. Also, 17 projects were discarded because of a lack of focus on industrial symbiosis. Twenty projects that focus on capacity building for industrial symbiosis were also excluded from the assessment because they do not deliver IT tools for IS. These 20 capacity-building projects and the 16 publicly funded projects for IT tool development received a funding of almost $€ 137$ million from the European Union (EU) since 2006.

One interview was carried out via Skype with the providers of the iNex platform. Specific information about the SymbioGis and Celero platforms was collected via email. Also, providers and researchers of the ZeroWin tool, Synergie ${ }^{\circledR}$, Nova Light and SymbioSys were contacted via email to

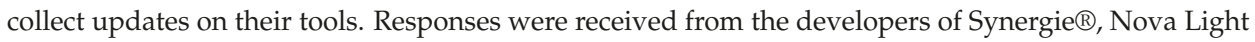
and SymbioSys. For the rest of the tools, publicly available information was obtained to carry out the assessment.

\subsection{Key Performance Indicators for Content Analysis}

To prepare the KPIs for the content analysis of the 20 IT tools for IS, the assessment criteria used by Grant et al. (2010) [33] was supplemented with some of the principles for park management by Van Eetvelde and colleagues (2005 and 2007) [5,36] and industrial symbiosis aspects used by Maqbool et al. (2017) [37]. The resulting assessment matrix is provided in Table 1.

Early in the analysis, it was found that the focus of the IT tools was not equally pointed at all of the five stages. Hence, a ranking with three levels was used to distinguish the level of focus of different IT tools on each of the five stages. These three levels are:

- 1 (no or low focus): minimal or no focus on the particular stage;

- 2 (moderate focus): supporting some aspects of the particular stage, but the main focus lies in another stage;

- 3 (strong focus): tools or projects with core objective and focus on this stage.

By introducing these three levels of measuring the focus on a given IS lifecycle stage, the desired flexibility for content analysis was introduced. An example of the IT tool developed in the EU funded H2020 project, EPOS (Enhanced energy and resource Efficiency and Performance in process industry Operations via onsite and cross-sectorial Symbiosis), is provided to elaborate how the three levels are used to reach a judgment about the focus of the IT tools. The EPOS IT tool optimises the generic models of industrial sectors, the so-called sector blueprints [47]. It does so by using techno-economic and environmental KPIs and identifies possible IS links between the unrelated industrial sectors, which is where the main focus of the EPOS tool lies. The EPOS User Club website also provides information on generic IS cases [48] that fall in the stage of follow up. The barrier of communication between unrelated sectors is overcome by anonymising data in the sector blueprints. Still, the stage where the main objective lies is synergy identification and thus received a score of 3 . This is because the 
effort for anonymising data to provide techno-economic assessment and barrier removal (both stages scored as 2) are all done to achieve the identification of IS possibilities. The follow up stage received a score of 1 because, although the EPOS User Club is part of the project website, it is not an integrated part of the EPOS IT tool. Though no direct reference to the implementation stage was found in the publicly available information, this stage also received a score of 1 and not a 0 because the project is still running and this possibility cannot yet be conclusively eliminated. Hence, it was decided to include three levels of assessing the focus, which helps to avoid making unsupported harsh claims about the focus of the IT tools under study.

Table 1. Assessment criteria for content analysis of industrial symbiosis (IS)-related projects and information technology (IT) tools.

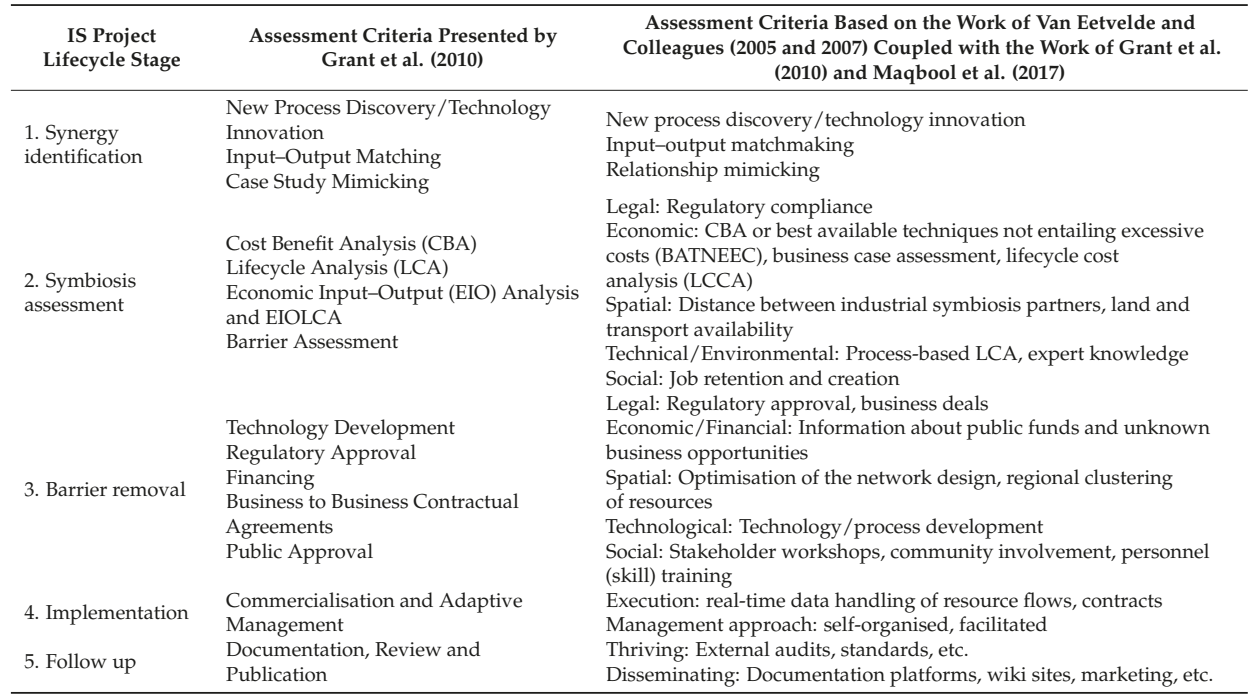

Once the content analysis of the IT tools was finished, the scores were aggregated to find the trends in the development of these IT tools.

\section{Results and Discussion}

\subsection{Content Analysis of the IT Tools}

Of the 20 IT tools under study, 8 of these are available on the market. Two of these eight IT tools-Synergie $($ (by International Synergies) and iNEX platform (by iNEX Circular)—are products of private companies that couple their IT tool with IS facilitation services for the customers. Synergie ${ }^{\circledR}$, an information and communication technology (ICT) resource management database and platform, is a web-based tool for IS facilitators. Additionally, the software allows companies to meet quality assurance protocol and audit requirements by offering database, project management and reporting functionalities to capture and store information about resources and to easily identify commercial opportunities for reuse [49]. Additionally, the R\&I project SHAREBOX is currently running to include more functionalities that enhance the IT tool Synergie ${ }^{\circledR}$. Now, Synergie ${ }$ can be used, inter alia, by plant operators and production managers to effectively monitor and trade process resource streams in real time within their own supply chains or with other companies in a symbiotic industrial system [50]. These factors allowed for a high ranking of Synergie®in all the lifecycle stages of IS, with the highest focus on synergy identification. The iNEX platform aims to solve the recycling problem and address the gap in knowledge for waste producers and waste recyclers/users. The iNex platform has been 
active for five years and provides synergy identification and knowledge support about methodologies to their customers. Because of the focus on matchmaking, the iNex platform scored the highest in synergy identification.

Two of the available IT tools-IS DATA repository and CIRCULATOR-are self-service tools and both are freely available platforms for knowledge sharing. The IS DATA repository provides freely available information about industrial symbiosis in a structured way [51]. The repository is being developed as part of a project organised by the Eco-Industrial Development Council Section of the International Society of Industrial Ecology [52]. The aim of the project is to allow for and enable the construction of varied end-use applications for the research and facilitation of industrial symbiosis. Hence, the IS DATA repository scored high on knowledge and communication barrier removal, as well as follow up, because of the publication of IS case studies. CIRCULATOR is a project funded by EIT RawMaterials and provides customised information to the user in the form of existing cases of business strategies for circular businesses [53]. Since it is a passive platform which provides information to users about general IS possibilities, its objective was evaluated to lie in breaking information barriers and thus scored highest in the barrier removal stage.

Two more operational IT tools (SMILE Resource Exchange and the Italian Platform for Industrial Symbiosis) are part of national programmes to enhance industrial symbiosis. SMILE Resource Exchange, part of the Irish National Program, is a free online platform for businesses to connect and identify opportunities for resource exchange [54]. The platform is coupled with a service provided by local consultants in different regions of Ireland. SMILE Platform breaks the information and communication barrier between stakeholders to provide an opportunity for synergy identification. The Italian Platform for Industrial Symbiosis, managed by the Italian National Agency for New Technologies, Energy and Sustainable Economic Development (ENEA), provides a platform for local businesses to search for synergies between the registered companies [55]. The platform is part of the project "Eco-innovazione Sicilia Project". The IT tool that is used by ENEA uses geo-referenced data to identify opportunities between companies and helps establish a network between companies and stakeholders. Hence, it ranked higher on synergy identification and barrier removal.

At the local level in Belgium, the initiative SYMBIOSE (BE) by the region of Flanders brings together local actors and supports IS realisation to help reduce the environmental impact of economic activities [56,57]. Symbiosis 3.0 is the web-platform of this initiative, providing a matchmaking service to the users. The initiative also helps in providing further information to interested parties about realising IS. Because of the heavy focus of the platform on the matchmaking service, it scored highest in the first stage of the IS project lifecycle. The last of the operational IT tools, SymbioSyS, incorporates tacit knowledge to identify symbiosis matches. It is a freely available tool developed for a variety of users who do not require expert knowledge to manage it [58]. The literature suggests that SymbioSyS is a freely available tool [58], however, the IT tool is only provided under agreement with the Universidad de Cantabria. The IT tool achieved the maximum score of 3 points in synergy identification because of the use of implicit knowledge to identify IS opportunities. From the literature, it was found that the SymbioSyS tool also uses geo-referenced data and, hence, scored high in the symbiosis assessment stage because it provides spatial assessment for synergy.

Six out of 20 IT tools included in this study were inaccessible, of which e-symbiosis, ZeroWin and Locimap have been developed through European funding. Presteo and SymbioGIS are a result of a national programme, and Nova Light is a product of a private company. The nonoperational tools still provide a world of knowledge for future research, for example, the eSymbiosis project, which successfully integrated tacit knowledge in the process of IS identification with the use of ontologies [38,39]. It received a score of 3 for the synergy identification stage. There are examples of new IT tools that use knowledge embedded in nonoperational IT tools. For example, Presteo, based on the work of Adoue [59], preceded the development of SymbioGis. The web-based tool for input-output (IO) matching, Presteo, was made for end users to identify symbiosis opportunities [33] and was followed by SymbioGis, a web-based GIS tool to facilitate industrial symbiosis in Geneva, Switzerland. 
The tool was developed as a result of a collaboration between the local government, university and the Sofies group [60]. Since the SymbioGis tool was developed to identify IO and service matches, it also provides a technical and geographical feasibility assessment and, hence, scored high on the first two stages of the IS lifecycle. Because of the functionality of the tool to provide information on locations for new facilities based on material flow in the region, it helps to remove the information barrier. Nova Light is a web-based platform developed by another private business. It was developed to provide matches between waste producers and consumers. Thus, a score of 3 was given for the synergy identification stage.

Six IT tools for IS that are under development are part of currently unfinished R\&I projects. The IT tool of FISSAC scored the highest score of 3 in synergy assessment because it is planned to be able to respond to resource efficiency and environmental performance concerns (by the help of lifecycle analysis (LCA)) and scored a 2 on synergy identification because it provides matches for the users of the geo-referenced platform [61]. The set of tools developed by the Maestri project aims to enhance the overall efficiency of industrial processes [62]. The combination of Maestri front end tools (MSM and ecoPROSYS) and the Internet of Things platform focuses the most on the assessment stage (3) and also provides support for breaking barriers for information exchange between different software tools (scored 2). The BISEPS tool is being developed to bring improvement in energy efficiency for businesses in business parks by clustering individual energy needs and demands [63]. Since the focus is on match-making, the score (3) was the highest for the synergy identification stage. The synergy assessment stage of Symby-Net, the platform developed by the Symbioptima project [64], scored the highest (3) because this IT tool provides lifecycle sustainability assessments of symbiotic networks. Symby-Net was developed to be used by industry managers as well as IS facilitators or park managers [64]. The ERMAT project will provide a web tool to be used for matchmaking purposes. This IT tool will be freely available for use by the public, while more information will be provided for a fee [65]. The IT tool for ERMAT scores highest on the first stage of the IS project lifecycle. The last of the IT tools being developed as part of an R\&I project is the EPOS toolbox, the content of which was discussed as an example in the methodology section.

\subsection{Scoring the IT Tools against IS Project Lifecycle Stages}

The results of the content analysis are summarised in Table 2. The acquired score gives the sum of the assigned scores for all IT tools for the respective lifecycle stage. The maximum score is calculated as $3 \times 20$, which would be the score had all the IT tools focused on the lifecycle stage with the highest emphasis. 
Sustainability 2019, 11, 131

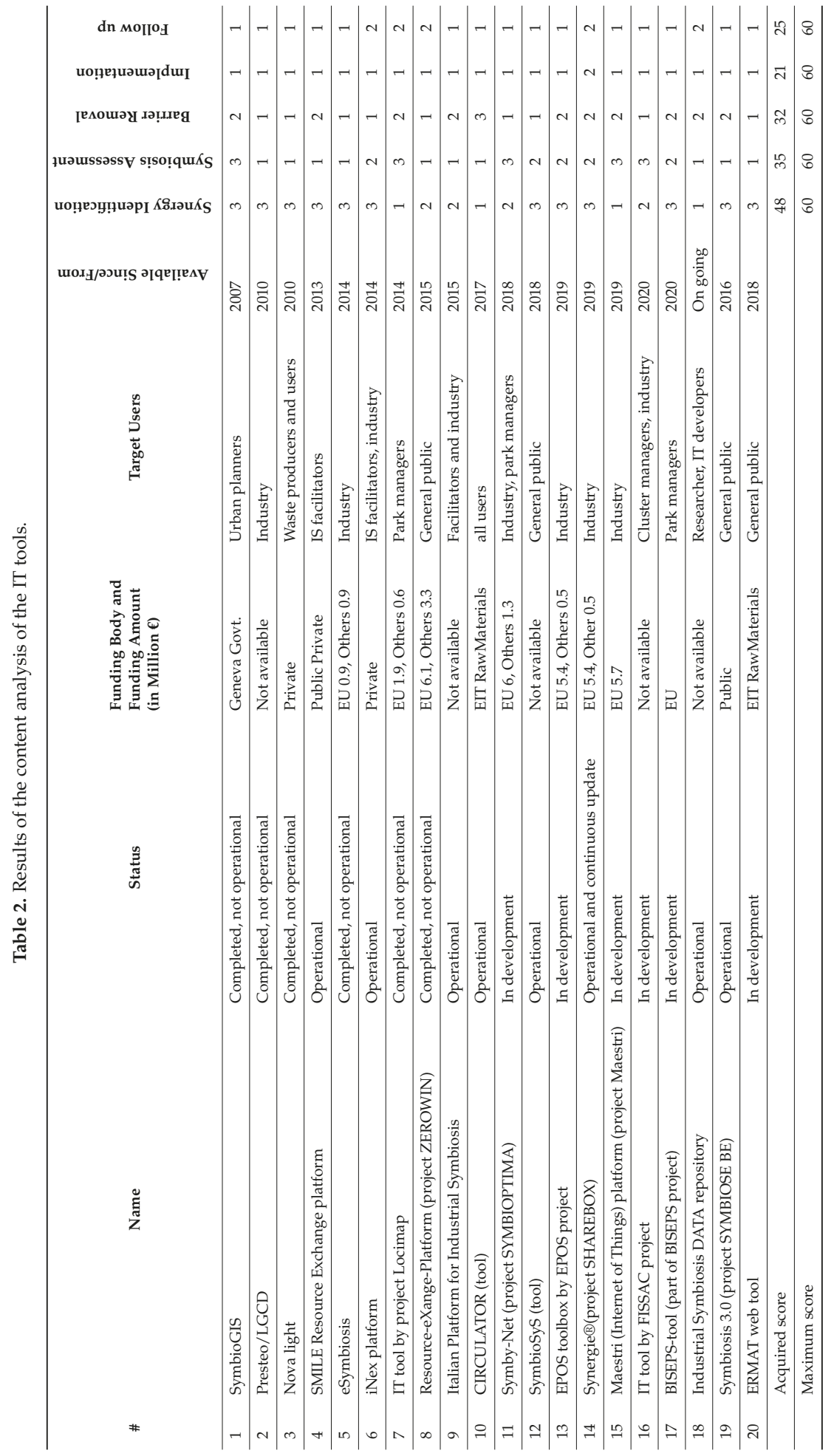


The results show that 12 IT tools have their main objective in the stage of synergy identification, with a prevalent commitment to matchmaking (48 points out of 60 ). Symbiosis assessment received second priority when developing the IT tools (35 points). These results coincide with the findings of Grant et al. (2010). The reason for this trend lies in the fact that matchmaking tools and assessment methodologies hold the most promise for innovation for academia, IT tool developers and the facilitators of industrial symbiosis. Closely following the IS assessment stage was barrier removal (32 points). The focus on the follow up stage is due to the dissemination function of the IT tools. The implementation stage of the IS project lifecycle shows the least focus (21 points). This is also not an unexpected result, as once the synergies are identified and assessed and barriers are removed, then contractual details and commercialisation by the industry does not pose a major difference as compared to normal business practices [26], resulting in the lowest focus being on the implementation stage [33] by IT tools for IS.

\subsection{Discrepancies Resolved by Newer IT Tools for IS}

Similar to the observations made by Grant et al. (2010), the assessment of newer IS-enabling IT tools still shows a heightened focus on the identification of symbiosis opportunities. This trend raises the legitimate question of if future research should still focus on developing more tools in the same trend, or should the focus be shifted to customising the existing tools to embed a management functionality to provide specific solutions to symbiosis partners. Learning from the available IT tools, it is evident that there is a lack of IT tools that provide support to implementation and management of the symbiosis activities, and more research and development efforts are required in that area.

The nontechnical information or tacit knowledge regarding industrial processes, business interactions, regulatory compliance, etc., is crucial for successful identification and application of IS. The older IT tools had a limited focus on the inclusion of nontechnical information in the development framework of the IT. Academia and industry have understood and expressed the importance of nontechnical barriers and drivers to IS $[25,26]$ and the inclusion of tacit knowledge in the process of opportunity identification. The newer IT tools developed under R\&I projects have focused on the inclusion of tacit knowledge for symbiosis identification and assessment, be it by the use of ontologies (projects e-symbiosis and SymbioSys) or by use of a recommender which identifies opportunities based on machine learning (AI) algorithms [66] (project SHAREBOX).

The other discrepancy in the older IT tools was the limited user profile, mainly targeted at the IT developer or engineer. This paper shows that more IT tools are being developed for use by industries that are referred to as participants by Grant et al. (2010) [33]. As mentioned by Van Capelleveen et al. (2018), organisations need to justify the time and resources invested in exploration of potential opportunities, the benefits of which are not certain [66]. This becomes even more difficult when an outsider requests information that may require time and resources and a risk of breach of confidentiality. IS opportunity exploration via IT tools can help industries control the information flow outside of the organisation [47]. As more IT tools are being developed for participants (EPOS toolbox, updates in Synergie under the project SHAREBOX, Maestri IoT, e-symbiosis platform), this should enhance the application of IS in various industries. The multidisciplinary and cross-sectoral nature of IS requires the IT tools to be used by a myriad of users. The knowledge that these users have also differs based on the sector to which they belong. Currently, the existing IT tools are specialised in solving sector-specific problems, while IS-enabling IT tools should address users from different sectors to solve cross-sectoral problems, which may result in the development of complex IT tools that require a high level of expertise to use. This dichotomy is shown in Figure 1. Passive online tools for matchmaking occupy the block of "nonspecific and easy to use IT tools"; however, these tools have shown to be less effective [26]. IT developers must ensure to avoid the effort invested to build tools that fit in the lower half of Figure 1. 


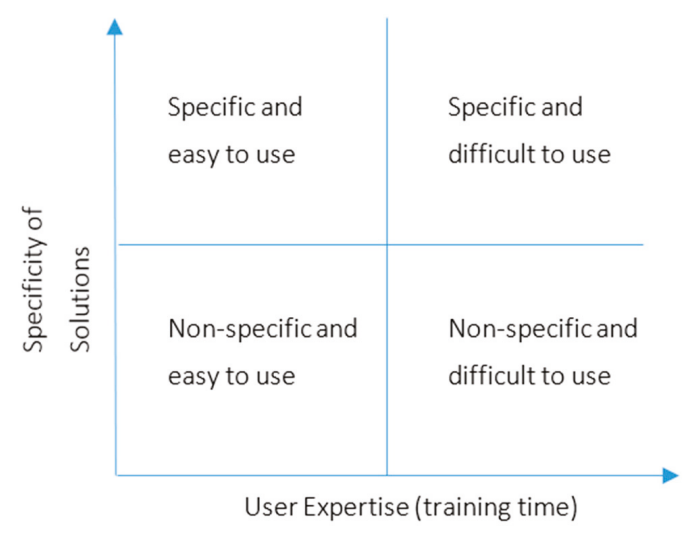

Figure 1. The relationship between specificity and user friendliness of IT tools for IS.

This figure, combined with the findings of this paper, will help researchers, industries and funding agencies to direct future endeavours in a more efficient and effective manner in order to pave Europe's way for resource efficiency and circularity.

The last research question to answer relates to the features of the successfully operational IT tools. The operational IT tools Synergie and the iNex platform are being developed by IS facilitators whose core business is coupled with the development of such a tool. The other operational IT tools for IS are part of local or national symbiosis programmes, such as Symbiose 3.0 and the SMILE platform, respectively. In both cases, the IT tools have a clear ownership and undergo continuous improvement. These are the two main features of successfully operational IT tools for IS. Another supporting mechanism to ensure that IT tools for IS find their way to the market and effectively support the uptake of IS in industry is through a variety of R\&I projects and local initiatives. These projects and programmes help to build capacity for IS in industry, small- and medium-sized enterprises, academia and local and national administrative bodies. These capacity-building efforts coupled with IT tools provide the advantage of focusing on all the stages of an IS project lifecycle that might not be fully supported by IT tools alone.

The research also showed that more IT tools are being developed with public funding. Five out of the six nonoperational IT tools included in this study were funded by some public organisation. It is crucial to use the knowledge created by these nonoperational tools and develop new and improved IT tools for IS. For example, as a follow up of SymbioGIS, since 2014, a consortium including the Sofies group has been busy developing a Celero platform to identify and facilitate industrial symbiosis and cleaner production among companies [67]. Effective mechanisms to support revitalising and improving publicly funded IT tools for IS need to be put in place in order to disseminate the benefits to the wider society.

\section{Conclusions}

This paper provided findings of the assessment and quantification of IS-enabling IT tools by focusing on the lifecycle stages of an IS project. The study enumerated the strengths and weaknesses of IT tools for IS; therefore, the KPIs and findings presented in this paper can be used as reference for self-assessment by applicants of R\&I projects for development of new IT tools for IS. The assessment matrix followed in this paper will also prove useful for funding agents and evaluators.

From the results, it can be concluded that the gaps identified by Grant et al. (2010) are being eliminated by the newer IT tools developed in Europe. Although the focus of IT tools still mainly centres on the identification of IS opportunities, the stage of implementation and management of a symbiosis activity is overlooked by IT development and research efforts. This gap can be easily bridged by updating existing and nonoperational IT tools for IS. 
It was observed that IT tools have a higher chance of remaining operational when the companies responsible for developing them can improve their core business by using it. Hence, coupling IT tools with the services of an IS facilitator or a local or national IS programme increases the chances of the tools remaining functional and economically viable. It was also observed that newer IT tools utilise tacit knowledge when identifying symbiosis opportunities and thus attempt to fill the gap in the older IS-supporting IT tools.

To conclude, the IT tools being developed in Europe are well on their way to proving effective for wider application. However, better mechanisms are still needed to ensure that IS-supporting IT tools developed with public funding reach the market and that the capacity developed from successful R\&I projects is made available to peers, industry and the general public for successful application of IS in Europe.

Author Contributions: Conceptualization, Writing-Original Draft Preparation, A.S.M.; Writing-Review \& Editing, A.S.M. and G.V.E.; Methodology, Formal Analysis, Investigation, A.S.M. and F.M.A.; Supervision, G.V.E.

Funding: The research leading to these results has received funding from the European Union's Horizon 2020 research and innovation programme under grant agreement no. 679386, EPOS project (Enhanced energy and resource Efficiency and Performance in process industry Operations via onsite and cross-sectorial Symbiosis). The sole responsibility of this publication lies with the authors. The European Union is not responsible for any use that may be made of the information contained herein.

Conflicts of Interest: The authors declare no conflict of interest.

\section{References}

1. Lowe, E.A.; Evans, L.K. Industrial ecology and industrial ecosystems. J. Clean. Prod. 1995, 3, 47-53. [CrossRef]

2. Chertow, M.R. Industrial Symbiosis: Literature and Taxonomy. Annu. Rev. Energy Environ. 2000, 25, 313-337. [CrossRef]

3. Puente, M.C.R.; Arozamena, E.R.; Evans, S. Industrial symbiosis opportunities for small and medium sized enterprises: Preliminary study in the Besaya region (Cantabria, Northern Spain). J. Clean. Prod. 2015, 87, 357-374. [CrossRef]

4. Lombardi, D.R.; Laybourn, P. Redefining Industrial Symbiosis. J. Ind. Ecol. 2012, 16, 28-37. [CrossRef]

5. Van Eetvelde, G.; Delange, E.; De Zutter, B.; Matthyssen, D.; Gevaert, L.; Schram, A.; Verstraeten, B.; Dierick, B.; Allaert, G.; Vanden Abeele, P.; et al. Groeiboeken Duurzame BedrijvenTerreinen Juridisch, Economisch, Ruimtelijk, Technisch Bekeken; Vanden Broele Grafische Groep: Brugge, Belgium, 2005.

6. Jacobsen, N.B. Industrial Symbiosis in Kalundborg, Denmark: A Quantitative Assessment of Economic and Environmental Aspects. J. Ind. Ecol. 2008, 10, 239-255. [CrossRef]

7. Chertow, M.; Ehrenfeld, J. Organizing Self-Organizing Systems. J. Ind. Ecol. 2012, 16, 13-27. [CrossRef]

8. Laybourn, P.; Lombardi, D.R. Industrial Symbiosis in European Policy. J. Ind. Ecol. 2012, 16, 11-12. [CrossRef]

9. European Commission. Circular Economy Package. January 2018. Available online: http://ec.europa.eu/ environment/circular-economy/index_en.htm (accessed on 21 December 2018).

10. European Commission. A Sustainable Bioeconomy for Europe: Strengthening the Connection between Economy, Society and the Environment; Directorate-General for Research and Innovation; Publications Office of the European Union: Luxembourg, 2018.

11. Publications Office of the European Union. Innovating for Sustainable Growth: A Bioeconomy for Europe; Publications Office of the European Union: Brussels, Belgium, 2012.

12. European Commission. A Roadmap for Moving to a Competitive Low Carbon Economy in 2050; Europese Commissie: Brussels, Belgium, 2011.

13. Directorate-General for Research and Innovation (European Commission). Pathways to Sustainable Industries: Energy Efficiency and CO2 Utilisation; European Commission: Brussels, Belgium, 2018.

14. European Commission. A European Strategy for Plastics in a Circular Economy; European Commission COM(2018) 28; European Commission: Brussels, Belgium, 2018.

15. EREP. European Resource Efficiency Platform-Manifesto \& Policy Recommendations; Policy Recommendations; European Commission: Brussels, Belgium, 2012. 
16. Funding Programmes-Eco-Innovation Action Plan-European Commission. Plan-European Commission. 2011. Available online: https://ec.europa.eu/environment/ecoap/about-action-plan/union-fundingprogrammes_en (accessed on 11 June 2018).

17. Davies, P.A. France Unveils Circular Economy Roadmap. 2018. Available online: https://www.globalelr. com/2018/04/france-unveils-circular-economy-roadmap/ (accessed on 11 Jun2018).

18. Mirata, M. Experiences from early stages of a national industrial symbiosis programme in the UK: determinants and coordination challenges. J. Clean. Prod. 2004, 12, 967-983. [CrossRef]

19. European Commission. Roadmap to Resource Efficient Europe; European Commission COM/2011/571; European Commission: Brussels, Belgium, 2011.

20. Baas, L. Planning and Uncovering Industrial Symbiosis: Comparing the Rotterdam and Östergötland regions. Bus. Strategy Environ. 2011, 20, 428-440. [CrossRef]

21. Shi, H.; Chertow, M.; Song, Y. Developing country experience with eco-industrial parks: A case study of the Tianjin Economic-Technological Development Area in China. J. Clean. Prod. 2010, 18, 191-199. [CrossRef]

22. Chertow, M.R.; Lombardi, D.R. Quantifying economic and environmental benefits of co-located firms. Environ. Sci. Technol. 2005, 39, 6535-6541. [CrossRef] [PubMed]

23. Li, Y.; Shi, L. The Resilience of Interdependent Industrial Symbiosis Networks: A Case of Yixing Economic and Technological Development Zone. J. Ind. Ecol. 2015, 19, 264-273. [CrossRef]

24. Sharib, S.; Halog, A. Enhancing value chains by applying industrial symbiosis concept to the Rubber City in Kedah, Malaysia. J. Clean. Prod. 2017, 41, 1095-1108. [CrossRef]

25. Van Eetvelde, G. Industrial Symbiosis. In Resource Efficiency of Processing Plants: Monitoring and Improvement; Krämer, S., Engell, S., Eds.; John Wiley \& Sons: Hoboken, NJ, USA, 2017.

26. Lombardi, R. Non-technical barriers to (and drivers for) the circular economy through industrial symbiosis: A practical input. Econ. Policy Energy Environ. 2017, 1, 171-189. [CrossRef]

27. Statistics Explained. Eurostat Business Demography. 2017. Available online: http:/ /ec.europa.eu/eurostat/ statistics-explained/index.php/Business_demography_statistics (accessed on 18 June 2018).

28. Stahel, W.R. The circular economy. Nature 2016, 531, 435-438. [CrossRef]

29. European Commission. Strategic Energy Technology Plan-Energy. Available online: https://ec. europa.eu/energy/en/topics/technology-and-innovation/strategic-energy-technology-plan (accessed on 11 June 2018).

30. European Commission. Erasmus+ Programme Guide; European Commission: Brussels, Belgium, 2018.

31. European Commission. Horizon 2020-European Commission. Horizon 2020. Available online: https: / / ec.europa.eu/programmes/horizon2020/en/ (accessed on 11 June 2018).

32. SPIRE. Sustainable Process Industry through Resources an Energy Efficiency. Available online: https: //www.spire2030.eu/ (accessed on 13 June 2018).

33. Grant, G.B.; Seager, T.P.; Massard, G.; Nies, L. Information and Communication Technology for Industrial Symbiosis. J. Ind. Ecol. 2010, 14, 740-753. [CrossRef]

34. Benedict, M.; Kosmol, L.; Esswein, W. Designing Industrial Symbiosis Platforms-From Platform Ecosystems to Industrial Ecosystems. In Proceeding of the Pacific Asia Conference on Information Systems, Yokohama, Japan, 26-30 June 2018.

35. Van Capelleveen, G.; Amrit, C.; Yazan, D.M. A Literature Survey of Information Systems Facilitating the Identification of Industrial Symbiosis. In From Science to Society; Springer: Cham, Switzerland, 2018; pp. 155-169.

36. Van Eetvelde, G.; Deridder, K.; Segers, S.; Maes, T.; Crivits, M. Sustainability scanning of eco-industrial parks. In Proceeding of the European Roundtable for Sustainable Consumption and Production (ERSCP), Basel, Switzerland, 20-22 June 2007; p. 20.

37. Maqbool, A.S.; Piccolo, G.E.; Zwaenepoel, B.; van Eetvelde, G. A Heuristic Approach to Cultivate Symbiosis in Industrial Clusters Led by Process Industry. In Proceeding of the Sustainable Design and Manufacturing (SDM-17), Bologna, Italy, 6-28 April 2017; pp. 579-588.

38. Trokanas, N.; Cecelja, F.; Raafat, T. Semantic input/output matching for waste processing in industrial symbiosis. Comput. Chem. Eng. 2014, 66, 259-268. [CrossRef]

39. Raafat, T.; Trokanas, N.; Cecelja, F.; Bimi, X. An ontological approach towards enabling processing technologies participation in industrial symbiosis. Comput. Chem. Eng. 2013, 59, 33-46. [CrossRef] 
40. Jensen, P.D.; Basson, L.; Hellawell, E.E.; Bailey, M.R.; Leach, M. Quantifying 'geographic proximity': Experiences from the United Kingdom's National Industrial Symbiosis Programme. Resour. Conserv. Recycl. 2011, 55, 703-712. [CrossRef]

41. Hackl, R.; Andersson, E.; Harvey, S. Targeting for energy efficiency and improved energy collaboration between different companies using total site analysis (TSA). Energy 2011, 36, 4609-4615. [CrossRef]

42. Golev, A.; Corder, G.D.; Giurco, D.P. Barriers to Industrial Symbiosis: Insights from the Use of a Maturity Grid. J. Ind. Ecol. 2015, 19, 141-153. [CrossRef]

43. Van Eetvelde, G.; de Zutter, B.; Deridder, K.; de Roeck, V.; Devos, D. Groeiboek Duurzame Bedrijuenterreinen, Juridisch Bekeken; Vanden Broele: Brugge, Belgium, 2005.

44. Siskos, I.; van Wassenhove, L.N. Synergy Management Services Companies: A New Business Model for Industrial Park Operators. J. Ind. Ecol. 2016, 21, 802-814. [CrossRef]

45. Paquin, R.L.; Howard-Grenville, J. The Evolution of Facilitated Industrial Symbiosis. J. Ind. Ecol. 2012, 16, 83-93. [CrossRef]

46. Harmonised Assessment of Regulatory Bottlenecks and Standardisation Needs for the Process Industry I SPIRE. 2019-2017. Available online: https: / www.spire2030.eu/harmoni (accessed on 4 July 2018).

47. Cervo, H.; Bungener, S.; Méchaussie, E.; Kantor, I.; Zwaenepoel, B.; Maréchal, F.; van Eetvelde, G. Virtual Sector Profiles for Innovation Sharing in Process Industry-Sector 01: Chemicals. In Proceeding of the Sustainable Design and Manufacturing (SDM-17), Bologna, Italy, 6-28 April 2017; pp. 569-578.

48. Generic IS Cases/EPOS. The EPOS User Club. Available online: https:/ / epos.userecho.com/knowledgebases /10-generic-is-cases (accessed on 28 November 2018).

49. SYNERGie®Software. International Synergies. 2018. Available online: https://www.international-synergies. com/software/ (accessed on 28 June 2018).

50. Introducing SHAREBOX-A Systemic Leap Forward for Industrial Symbiosis. International Synergies. 22 March 2016. Available online: https://www.international-synergies.com/news/introducing-sharebox-asystemic-leap-forward-for-industrial-symbiosis/ (accessed on 28 June 2018).

51. What Is ISDATA I ISDATA. Available online: http:/ / isdata.org (accessed on 31 July 2018).

52. Davis, C. The Industrial Symbiosis Data Repository/ Primary Database Project. In Proceeding of the 2013 Industrial Symbiosis Research Symposium, Ulsan, Korea, 23-24 June 2013. Database Project Handout.

53. Mix Your Strategies-Circulator. Available online: http:/ / circulator.eu//mix-your-strategies (accessed on 31 July 2018).

54. Macroom E Enterprise Centre. About SMILE Resource Exchange-Save Money, Divert Waste from Landfill—Smile Resource Exchange. Available online: http:/ /www.smileexchange.ie/about-us (accessed on 31 July 2018).

55. Cutaia, L.; Luciano, A.; Barberio, G.; Sbaffoni, S.; Mancuso, E.; Scagliarino, C.; La Monica, M. The experience of the first industrial symbiosis platform in Italy. Environ. Eng. Manag. J. 2015, 14, 1521-1533. [CrossRef]

56. OVAM. Symbiose Verzilvert Reststromen (Symbiosis to Valorise Waste). Available online: https:/ /ovam.be/ symbiose-verzilvert-reststromen (accessed on 2 August 2018).

57. Symbiose-Catalisti. CATALISTI. December 2016. Available online: http:/ / catalisti.be/project/symbiose/ (accessed on 30 November 2018).

58. Álvarez, R.; Ruiz-Puente, C. Development of the Tool SymbioSyS to Support the Transition Towards a Circular Economy Based on Industrial Symbiosis Strategies. Waste Biomass Valorization 2017, 8, 1521-1530. [CrossRef]

59. Adoue, C. Méthodologie d'identification de Synergies éco-Industrielles Réalisables Entre Entreprises sur le Territoire Français. Ph.D. Thesis, Université de Technologie de Troyes, Troyes, France, 2004.

60. Massard, G.; Erkman, S. A regional industrial symbiosis methodology and its implementation in Geneva, Switzerland. In Proceeding of the 3rd International Conference on Life Cycle Management, Zurich, Switzerland, 27-29 August 2007; Volume 27.

61. Sánchez, B.J.; Hiniesto, D.; Guedella, E. D1.8: Initial outline of FISSAC Industrial Symbiosis Model and Methodology/Report. 2017. Available online: http://fissacproject.eu/wp-content/uploads/2017/09/ FISSAC-D1.8-Initial-outline-of-FISSAC-IS-Model-Methodology.pdf (accessed on 21 December 2018).

62. Baptista, A.J.; Lourenco, E.J.; Pecas, P.; Silva, E.J.; Estrela, M.A.; Holgado Granados, M.; Benedetti, M.; Evans, S. MAESTRI Efficiency Framework as a support tool for Industrial Symbiosis implementation. 2017. Available online: https: / www.repository.cam.ac.uk/handle/1810/267299 (accessed on 21 December 2018). 
63. BISEPS Tool-Biseps. BISEPS Project Website. Available online: http://www.biseps.eu/biseps-tool/ (accessed on 30 November 2018).

64. Brondi, C.; Cornago, S.; Ballarino, A.; Avai, A.; Pietraroia, D.; Dellepiane, U.; Niero, M. Sustainability-based Optimization Criteria for Industrial Symbiosis: The Symbioptima Case. Procedia CIRP 2018, 69, 855-860. [CrossRef]

65. Grazia, B.; Jacobsson, E.; Björn, H.; Karhu, M.; Meneve, J.; Kinnunen, P.; Karu, V. Sustainability and business for residual materials: The ERMAT project approach. 2017. Available online: http://www.enea.it/it/ seguici/events/sun_simbiosiindustriale_25ott17/ERMAT_ENEA_SUN.pdf (accessed on 28 June 2018).

66. Van Capelleveen, G.; Amrit, C.; Yazan, D.M.; Zijm, H. The influence of knowledge in the design of a recommender system to facilitate industrial symbiosis markets. Environ. Model. Softw. 2018, 110, 139-152. [CrossRef]

67. The Celero Platform: Detection of Industrial Symbiosis and Cleaner Production Opportunities. Sofies. Available online: https://sofiesgroup.com/en/projects/ecoman-platform-detection-industrial-symbiosiscleaner-production-opportunities / (accessed on 28 June 2018).

(C) 2018 by the authors. Licensee MDPI, Basel, Switzerland. This article is an open access article distributed under the terms and conditions of the Creative Commons Attribution (CC BY) license (http://creativecommons.org/licenses/by/4.0/). 